\title{
New computational studies to support cyclin-dependent kinase 9 inhibitor screening and design
}

\author{
MÁRK FÁBIÁN ${ }^{1}$, B ALÁZS B ALOGH ${ }^{2}$, ZSÓFIA CZUDOR ${ }^{1}$, LÁSZLÓ ŐRFI ${ }^{1,3^{*}}$ \\ ${ }^{1}$ Department of Pharmaceutical Chemistry, Semmelweis University, Högyes Endre St. 9. 1092, Budapest, Hungary \\ ${ }^{2}$ Department of Organic Chemistry, Semmelweis University, Högyes Endre St. 7. 1092, Budapest, Hungary \\ ${ }^{3}$ Vichem Chemie Research Ltd, Rákóczi utca 5. 8200, Veszprém, Hungary \\ *Corresponding author: László Őrfi, email: orfi.laszlo@pharma.semmelweis-univ.hu
}

Received: 13 March 2019 / Accepted: 19 March 2019 / Published online: 3 April 2019

\begin{abstract}
:
Aims: Cyclin-dependent kinase 9 (CDK9) plays a major role in the regulation of transcription. Its overexpression - which occurs in several types of cancer - increases the levels of certain antiapoptotic proteins that can lead to tumorigenesis, therefore the identification of new, more potent and more selective inhibitors is essential.

Methods: In this study we present a computational approach, which can facilitate lead selection and optimization.

Results: First, a pharmacophore hypothesis based on the active compounds has been developed to identify the key features for the ligand-target interaction. This was followed by the docking of the compounds into the active site of CDK9, the poses and interactions with the amino acids were compared with those of the co-crystallized ligand. The mode of their binding further explained the characteristics of these inhibitors while the docking scores can be a factor in the selection of active compounds in the future. Finally, a field-based QSAR model was also created, to predict the activity of inhibitor candidates.

Conclusion: With our current work we deepened our knowledge about the interactions between CDK9 and its inhibitors, which can contribute to the discovery of novel CDK9 inhibitors.
\end{abstract}

Keywords: CDK9 inhibitor, docking, QSAR, pharmacophore model

\section{INTRODUCTION}

Cyclin-dependent kinases (CDK) are characterized as Ser/Thr kinases. Twenty members of this group have been discovered so far [1]. In most cases their activity depends on cyclins, which bind to them and act as regulatory subunits to control kinase activity and substrate specificity. These CDKcyclins complexes are usually involved in cell cycle and transcription regulation, therefore their overexpression or amplification can easily lead to improper operation of cell cycle or transcription, which may cause uncontrolled proliferation and thus tumor formation [2].

CDK9 can be expressed in two isoforms, a lighter $42 \mathrm{kDa}$ protein and a heavier $55 \mathrm{kDa}$ protein [3]. Both are capable of forming complexes with cyclin T1, T2a, T2b and K [4]. The structure of CDK9 shows typical features of its class. There is an N-terminal lobe (residues 16-108), which contains five segments of $\beta$-sheet completed with a single $\alpha$-helix, while the C-terminal lobe (residues 109-330) is comprised of four $\beta$-strands and seven main $\alpha$-helices [5]. The ATP binding site is located in a cleft between the two lobes of the protein and there is also a loop behind them called 'hinge'. All these three parts are involved in the ATP binding. The binding pocket has a characteristic sickle-like shape, with a volume of approximately $360 \AA^{3}$ (calculated by Schrödinger's SiteMap application) $[6,7]$. It is relatively narrow and flat with a hydrophobic region in the middle. The structure of CDK9 is very similar to that of CDK2, as they have $40 \%$ sequence identity [5].

The determination of its crystallographic structure became possible only 14 years after the discovery of CDK9 [5]. Sixteen crystal structures of it were deposited in the RCSB database until present day. For our project we retrieved one from the Protein Database (PDB ID: 4BCF). It is in complex with cyclin $\mathrm{T}$ and what is more important with a 2-amino-4-heteroaryl-pyrimidine inhibitor. We have selected this structure, because the co-crystallized inhibitor was similar to our ligands, so it probably binds with similar interactions to the protein.

Physiologically, cyclin $\mathrm{T}$ is needed for the activation of the enzyme by the phosphorylation of $\mathrm{Thr}^{186}$. After that the complex can fulfill its role [8], which is the following: CDK9/cyclin $\mathrm{T}$ is a part of 
a larger protein complex called positive transcription elongation factor $b(\mathrm{P}-\mathrm{TEFb})$ in which the CDK9 can phosphorylate the C-terminal domain (CTD) of RNA polymerase II (RNAPII). This is a key regulatory mechanism during elongation [4]. CDK9 mediated phosphorylation of the CTD in RNAPII increases the levels of antiapoptotic proteins such as Mcl-1 and XIAP. If CDK9 is overexpressed or amplified, this process can lead to tumorigenesis $[9,10]$. Additionally, through the hexamethylene bisacetamide-inducible protein 1 (HEXIM1), CDK9 can be associated with the replication of Human Immunodeficiency Virus (HIV) [11]. Therefore, CDK9 inhibitors could be used in HIV and cancer therapy as well.

Several CDK and CDK9 inhibitors have been developed so far. Roscovitine (seliciclib) was the first CDK inhibitor to enter clinical trials [12], but palbociclib was the first that obtained FDA approval [13, 14]. As for CDK9, one of the most significant inhibitors is dinaciclib that reached the most advanced clinical phase [13, 15]. One of the main problems regarding the current CDK9 inhibitors is the lack of selectivity, which may lead to severe side effects during therapy [16]. Therefore, the need for more selective CDK inhibitors has been emerged. Our work aims to provide a useful method in compound prescreening to reduce the time and costs of lead selection and optimization.

\section{MATERIALS AND METHODS}

\subsection{Data set}

All models we created were based on a set of 41 CDK9 inhibitors that was synthesized by our research group [17]. We kept the numbering of the compounds as it is in the abovementioned paper. The structures and $\mathrm{IC}_{50}$ values of the compounds are listed in Table I.

During our work we used Schrödinger's Maestro software [18] to run calculations and create models.

\subsection{Protein and ligand preparation}

The first task was to prepare the crystal structure of 4BCF with Protein Preparation Wizard [19], which included preprocessing, $\mathrm{H}$-bond assessment and restrained minimi- zation. Default settings were used in all parts of the preparation. Ligand structures were drawn with Schrödinger's Maestro graphical user inter-

Table I Structure and CDK9 inhibitory activity of N-aryl pyrimidinamines [17].<smiles>[R9]c1cc([Hg])c(-c2ccnc(Nc3ccc(S(=O)(=O)N[AlH4])cc3)n2)c([Y4])c1O</smiles>

\begin{tabular}{|c|c|c|c|c|c|c|}
\hline ID & R1 & R2 & R3 & R4 & Ar & $\begin{array}{l}\mathrm{IC}_{50} \\
\text { (nM) }\end{array}$ \\
\hline 21 & $\mathrm{MeO}$ & $\mathrm{H}$ & $\mathrm{H}$ & $\mathrm{H}$ & 3,4-dimethyl-isoxazole & 3 \\
\hline 22 & $\mathrm{MeO}$ & $\mathrm{F}$ & $\mathrm{H}$ & $\mathrm{H}$ & 3,4-dimethyl isoxazole & 2 \\
\hline 23 & $\mathrm{MeO}$ & $\mathrm{H}$ & $\mathrm{F}$ & $\mathrm{H}$ & 3,4-dimethyl-isoxazole & 9 \\
\hline 24 & $\mathrm{MeO}$ & $\mathrm{H}$ & $\mathrm{H}$ & $\mathrm{F}$ & 3,4-dimethyl-isoxazole & 1 \\
\hline 25 & $\mathrm{MeO}$ & $\mathrm{F}$ & $\mathrm{F}$ & $\mathrm{H}$ & 3,4-dimethyl-isoxazole & 8 \\
\hline 26 & $\mathrm{MeO}$ & $\mathrm{H}$ & $\mathrm{F}$ & $\mathrm{F}$ & 3,4-dimethyl-isoxazole & 1 \\
\hline 27 & $\mathrm{MeO}$ & $\mathrm{CL}$ & $\mathrm{H}$ & $\mathrm{H}$ & 3,4-dimethyl-isoxazole & 12 \\
\hline 28 & $\mathrm{MeO}$ & $\mathrm{H}$ & $\mathrm{H}$ & $\mathrm{Cl}$ & 3,4-dimethyl-isoxazole & 25 \\
\hline 29 & $\mathrm{MeO}$ & $\mathrm{MeO}$ & $\mathrm{H}$ & $\mathrm{H}$ & 3,4-dimethyl-isoxazole & 9 \\
\hline 30 & EtO & $\mathrm{F}$ & $\mathrm{H}$ & $\mathrm{H}$ & 3,4-dimethyl-isoxazole & 8 \\
\hline 31 & $\mathrm{EtO}$ & $\mathrm{H}$ & $\mathrm{H}$ & $\mathrm{F}$ & 3,4-dimethyl-isoxazole & 2 \\
\hline 32 & $\mathrm{EtO}$ & $\mathrm{Cl}$ & $\mathrm{H}$ & $\mathrm{H}$ & 3,4-dimethyl-isoxazole & 17 \\
\hline 33 & iPro & $\mathrm{F}$ & $\mathrm{H}$ & $\mathrm{H}$ & 3,4-dimethyl-isoxazole & 49 \\
\hline 34 & $\mathrm{H}$ & $\mathrm{H}$ & iPro & $\mathrm{F}$ & 3,4-dimethyl-isoxazole & 458 \\
\hline 35 & $\mathrm{MeS}$ & $\mathrm{F}$ & $\mathrm{H}$ & $\mathrm{H}$ & 3,4-dimethyl-isoxazole & 13 \\
\hline 36 & $\mathrm{Me}$ & $\mathrm{F}$ & $\mathrm{H}$ & $\mathrm{H}$ & 3,4-dimethyl-isoxazole & 6 \\
\hline 37 & $\mathrm{~F}$ & $\mathrm{~F}$ & $\mathrm{H}$ & $\mathrm{H}$ & 3,4-dimethyl-isoxazole & 11 \\
\hline 38 & $\mathrm{~F}$ & $\mathrm{MeO}$ & $\mathrm{H}$ & $\mathrm{F}$ & 3,4-dimethyl-isoxazole & 21 \\
\hline 39 & $\mathrm{Cl}$ & $\mathrm{F}$ & $\mathrm{H}$ & $\mathrm{H}$ & 3,4-dimethyl-isoxazole & 55 \\
\hline 40 & $\mathrm{MeO}$ & $\mathrm{Cl}$ & $\mathrm{H}$ & $\mathrm{H}$ & 3,4-dimethyl-isoxazole & 50 \\
\hline 41 & $\mathrm{MeO}$ & $\mathrm{H}$ & $\mathrm{H}$ & $\mathrm{H}$ & 4,5-dimethyl-isoxazole & 4 \\
\hline 42 & $\mathrm{MeO}$ & $\mathrm{F}$ & $\mathrm{H}$ & $\mathrm{H}$ & 4,5-dimethyl-isoxazole & 3 \\
\hline 43 & $\mathrm{MeO}$ & $\mathrm{F}$ & $\mathrm{H}$ & $\mathrm{H}$ & benzo[d]isoxazole & 5 \\
\hline 44 & $\mathrm{MeO}$ & $\mathrm{H}$ & $\mathrm{H}$ & $\mathrm{H}$ & thiazole & 33 \\
\hline 45 & $\mathrm{MeO}$ & $\mathrm{F}$ & $\mathrm{H}$ & $\mathrm{H}$ & thiazole & 122 \\
\hline 46 & $\mathrm{MeO}$ & $\mathrm{H}$ & $\mathrm{H}$ & $\mathrm{F}$ & thiazole & 2 \\
\hline 47 & $\mathrm{EtO}$ & $\mathrm{F}$ & $\mathrm{H}$ & $\mathrm{H}$ & thiazole & 210 \\
\hline 48 & $\mathrm{EtO}$ & $\mathrm{Cl}$ & $\mathrm{H}$ & $\mathrm{H}$ & thiazole & 378 \\
\hline 49 & $\mathrm{MeO}$ & $\mathrm{H}$ & $\mathrm{H}$ & $\mathrm{H}$ & * & 12 \\
\hline 50 & $\mathrm{MeO}$ & $\mathrm{F}$ & $\mathrm{H}$ & $\mathrm{H}$ & * & 6 \\
\hline 51 & $\mathrm{MeO}$ & $\mathrm{H}$ & $\mathrm{F}$ & $\mathrm{H}$ & * & 9 \\
\hline 52 & $\mathrm{MeO}$ & $\mathrm{H}$ & $\mathrm{H}$ & $\mathrm{F}$ & $*$ & 2 \\
\hline 53 & $\mathrm{MeO}$ & $\mathrm{F}$ & $\mathrm{F}$ & $\mathrm{H}$ & * & 10 \\
\hline 54 & $\mathrm{MeO}$ & $\mathrm{H}$ & $\mathrm{F}$ & $\mathrm{F}$ & * & 0.4 \\
\hline 55 & $\mathrm{MeO}$ & $\mathrm{MeO}$ & $\mathrm{H}$ & $\mathrm{H}$ & * & 14 \\
\hline 56 & EtO & $F$ & $\mathrm{H}$ & $\mathrm{H}$ & * & 2 \\
\hline 57 & EtO & $\mathrm{Cl}$ & $\mathrm{H}$ & $\mathrm{H}$ & $*$ & 5 \\
\hline
\end{tabular}

*: 2-methyl-[1,3,4]thiadiazol 
Continuation from previous page

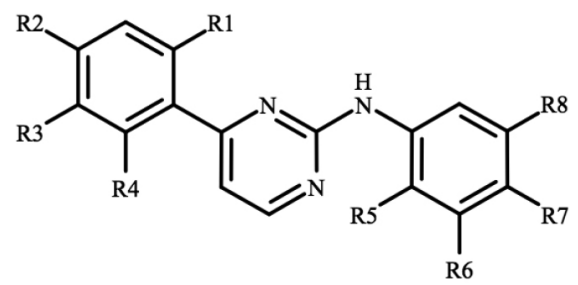

\begin{tabular}{l|l|l|l|l|l|l|l|l|l}
\hline ID & R1 & R2 & R3 & R4 & R5 & R6 & R7 & R8 & $\begin{array}{l}\text { IC }_{50} \\
\text { (nM) }\end{array}$ \\
\hline 58 & $\mathrm{MeO}$ & $\mathrm{H}$ & $\mathrm{H}$ & $\mathrm{H}$ & $\mathrm{F}$ & $\mathrm{H}$ & $\mathrm{MeO}$ & $* * *$ & 1576 \\
\hline 66 & $\mathrm{MeO}$ & $\mathrm{H}$ & $\mathrm{H}$ & $\mathrm{H}$ & $\mathrm{H}$ & $* *$ & $\mathrm{H}$ & $\mathrm{H}$ & 3 \\
\hline 67 & $\mathrm{MeO}$ & $\mathrm{F}$ & $\mathrm{H}$ & $\mathrm{H}$ & $\mathrm{H}$ & $* *$ & $\mathrm{H}$ & $\mathrm{H}$ & 4 \\
\hline 68 & $\mathrm{MeO}$ & $\mathrm{H}$ & $\mathrm{H}$ & $\mathrm{F}$ & $\mathrm{H}$ & $* *$ & $\mathrm{H}$ & $\mathrm{H}$ & 2 \\
\hline
\end{tabular}

**: 1H-benzimidazole-1-yl-methyl

***: carboxamide

face (GUI), then the LigPrep module was used to generate energy-minimized 3D conformations of each compound. To perform this, the optimized potential for liquid simulations 2005 (OPLS-2005) force field [20] was adopted. One stereoisomer per ligand was studied. As for ionization forms, we generated the most possible state of each molecule with Ionizer at target $\mathrm{pH}$ of 7.4. The negative logarithm values $\left(\mathrm{pIC}_{50}\right)$ of the previously published inhibitory activities were calculated and used for the model building [17]. Flexible Ligand Alignment procedure of the Maestro GUI was utilized for the superposition of the ligands. The best alignment was received by using the 'Common scaffold alignment' with 'fuzzy matching' option.

\subsection{Docking}

Schrödinger's Grid-based Ligand Docking with Energetics (GLIDE) was used in the docking studies. Firstly, we created the grid box for the docking. The co-crystallized ligand was used to determine the place of the binding pocket and after measuring the size of our ligands we decided to set the size of the grid box for $20 \times 20 \times 20 \AA$ to surely have enough space in it for all ligands. The co-crystallized ligand was re-docked with both the 'score in place' and the standard precision (SP) procedures in order to validate our model. Then all the examined ligands were docked via both the SP and the extra precision $(\mathrm{XP})$ methods. Flexible ligand sampling was used with the standard settings during all docking procedures.

\subsection{Pharmacophore Hypothesis}

Schrödinger's Phase module [21] was used for pharmacophore model development. We developed two kinds of pharmacophore hypotheses. For the first one, we used the previously aligned ligands and defined entries with $\mathrm{pIC}_{50}$ value above 7.0 as active. Then several hypotheses were developed. As for the second kind, we used the XP docked ligand conformations for the model, thus there was no need to generate conformers during the development of these pharmacophore hypotheses. In both cases there were 4-7 features in the hypotheses, which matched $66 \%, 75 \%$ or $90 \%$ of the active ligands. Hereby we present one model, which we found the best based on Survival score and compatibility with our data from docking and pharmacophore hypothesis.

\subsection{Field-Based QSAR}

Our Quantitative Structure-Activity Relationship (QSAR) models were developed with Schrödinger's Field-based module. The previously aligned 41 ligands were used for this part. The activity property was $\mathrm{pIC}_{50}$. The data set was randomly divided into training (66\%) and test sets (33\%). Partial least squares regression (PLS) method with up to 6 factors with standard settings was used, except that

Table II Statistical parameters of the final field-based QSAR model

\begin{tabular}{l|l}
\hline Number of PLS factors & 4 \\
\hline Standard deviation of the regression $(\mathrm{SD})$ & 0.3847 \\
\hline Training set regression $\left(\mathrm{R}^{2}\right)$ & 0.8046 \\
\hline Cross-validated $\mathrm{R}^{2}\left(\mathrm{R}^{2}-\mathrm{CV}\right)$ & $\mathbf{0 . 4 5 6 7}$ \\
\hline $\mathrm{R}^{2}$ with scrambled activities $\left(\mathrm{R}^{2}\right.$ scramble) & $\mathbf{0 . 4 1 5 4}$ \\
\hline $\begin{array}{l}\text { Stability of the model predictions to changes in the training set composition (maximum value } \\
\text { is } 1 \text {, meaning stable) }\end{array}$ & $\mathbf{0 . 7 9 9}$ \\
\hline F- variance ratio (large values indicate a more statistically significant regression) & 23.7 \\
\hline P- significance level of variance ratio (smaller values indicate a greater degree of confidence) & $7.19 \mathrm{E}-08$ \\
\hline Test set regression $\left(\mathrm{Q}^{2}\right)$ & $\mathbf{0 . 5 3 2 9}$ \\
\hline
\end{tabular}




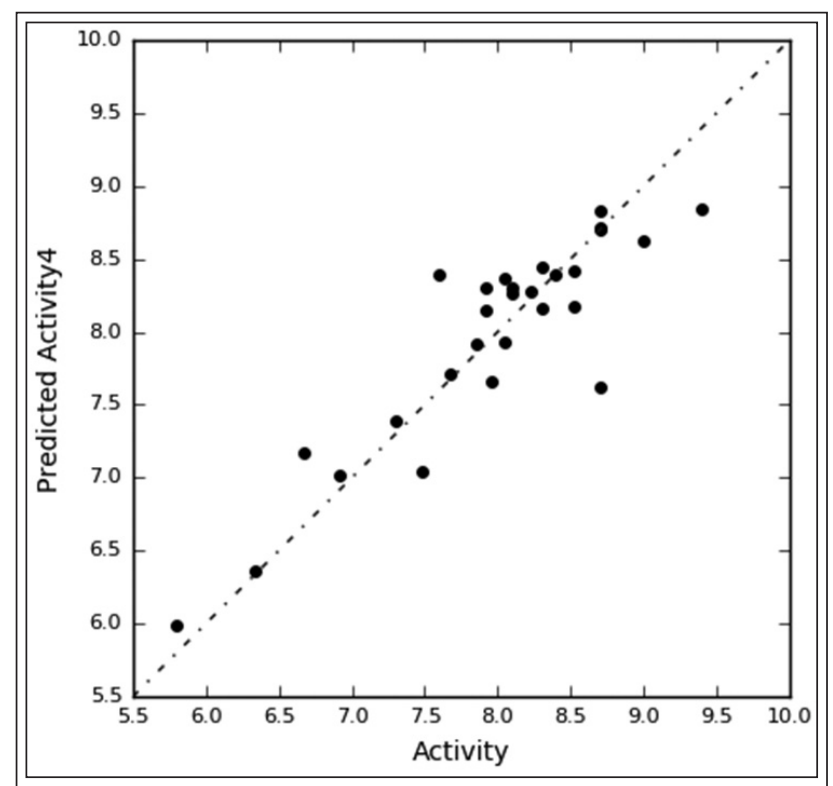

Figure 1 QSAR - Scatter plot of the training set

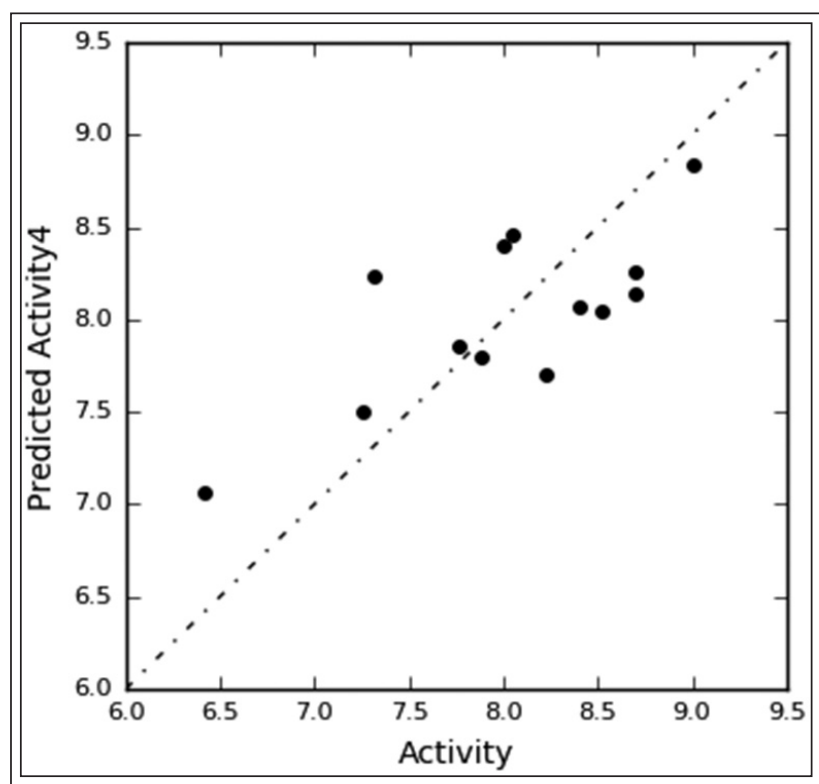

Figure 2 QSAR - Scatter plot of the test set we eliminated variables with |t-valuel $<2$. The model with the best statistical attributes was selected as the final one.

\section{RESULTS AND DISCUSSION}

\subsection{Field-Based QSAR}

As shown in Table II, the model we found best, offered good predictive power and descriptive capability. The $\mathrm{R}^{2}$ value for the regression of the training set was above 0.8 and 0.53 for the test set, the cross-validated $R^{2}$ and scrambled $R^{2}$ values were also within the range of acceptance. These data together with the Stability and $F$ and $P$ values were indicating the reliability and robustness of our model. The graphical representation of the $\mathrm{R}^{2}$ (Figure 1) and $\mathrm{Q}^{2}$ (Figure 2) also indicated a good alignment with only a few outliers. Moreover, after visualization of the model, we could get more valuable information about CDK9 inhibitors (Figure 3). As it is illustrated, generally,

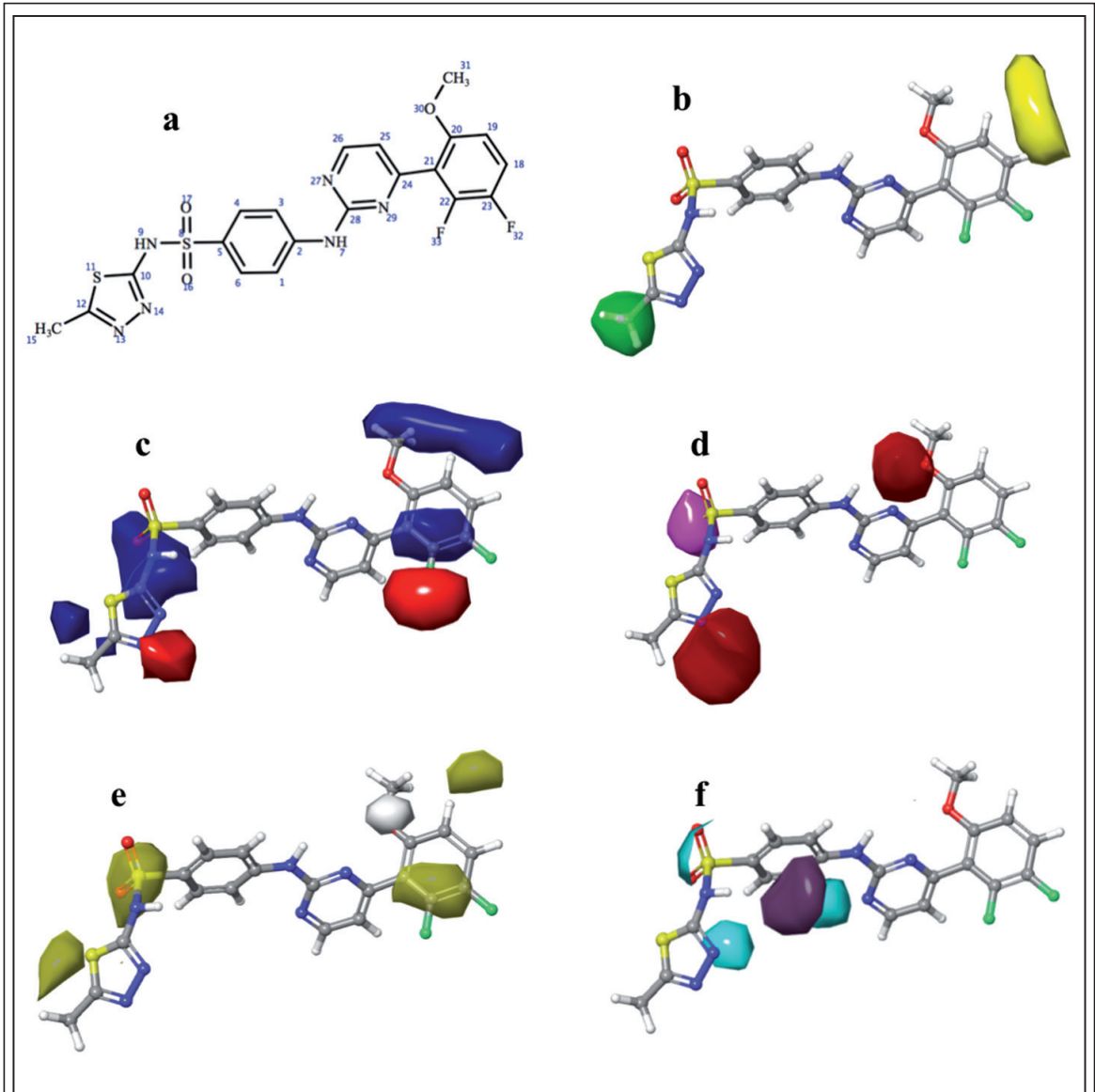

Figure 3 QSAR Visualization via Contour maps using compound 54 as an example: a: numbering of compound 54, b: Gaussian Steric Force Field, green: favorable, yellow: unfavorable c: Gaussian Electrostatic Force Field, blue: favorable, red: unfavorable d: Gaussian H-bond Acceptor, red: favorable, magenta: unfavorable e: Gaussian Hydrophobic, yellow: favorable, white: unfavorable f: Gaussian H-bond Donor, purple: favorable, cyan: unfavorable 


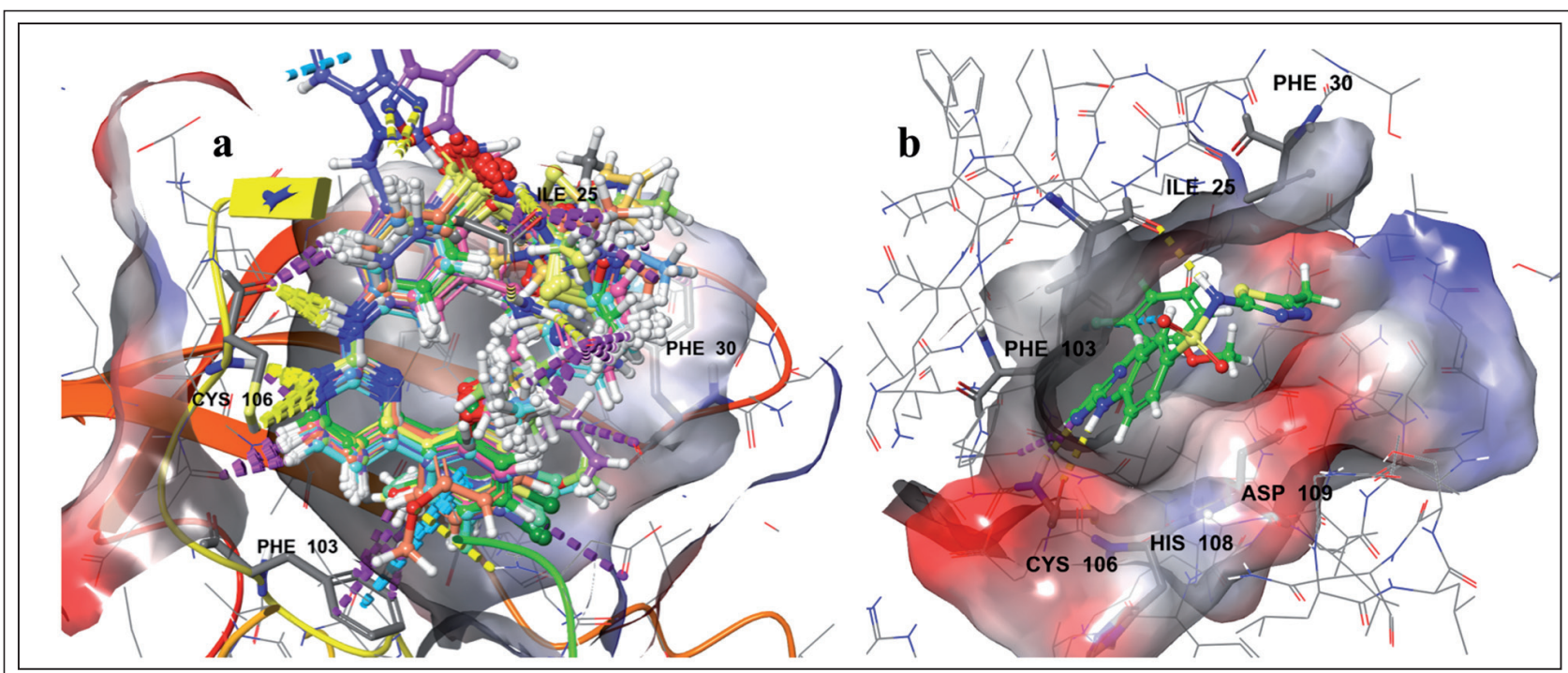

Figure 4 XP docking results a: side view of the site with all docked ligands included $b$ : top view of the site, which reveals the characteristic narrow, flat shape of the pocket (together with compound 54 as an example of ligand positioning)

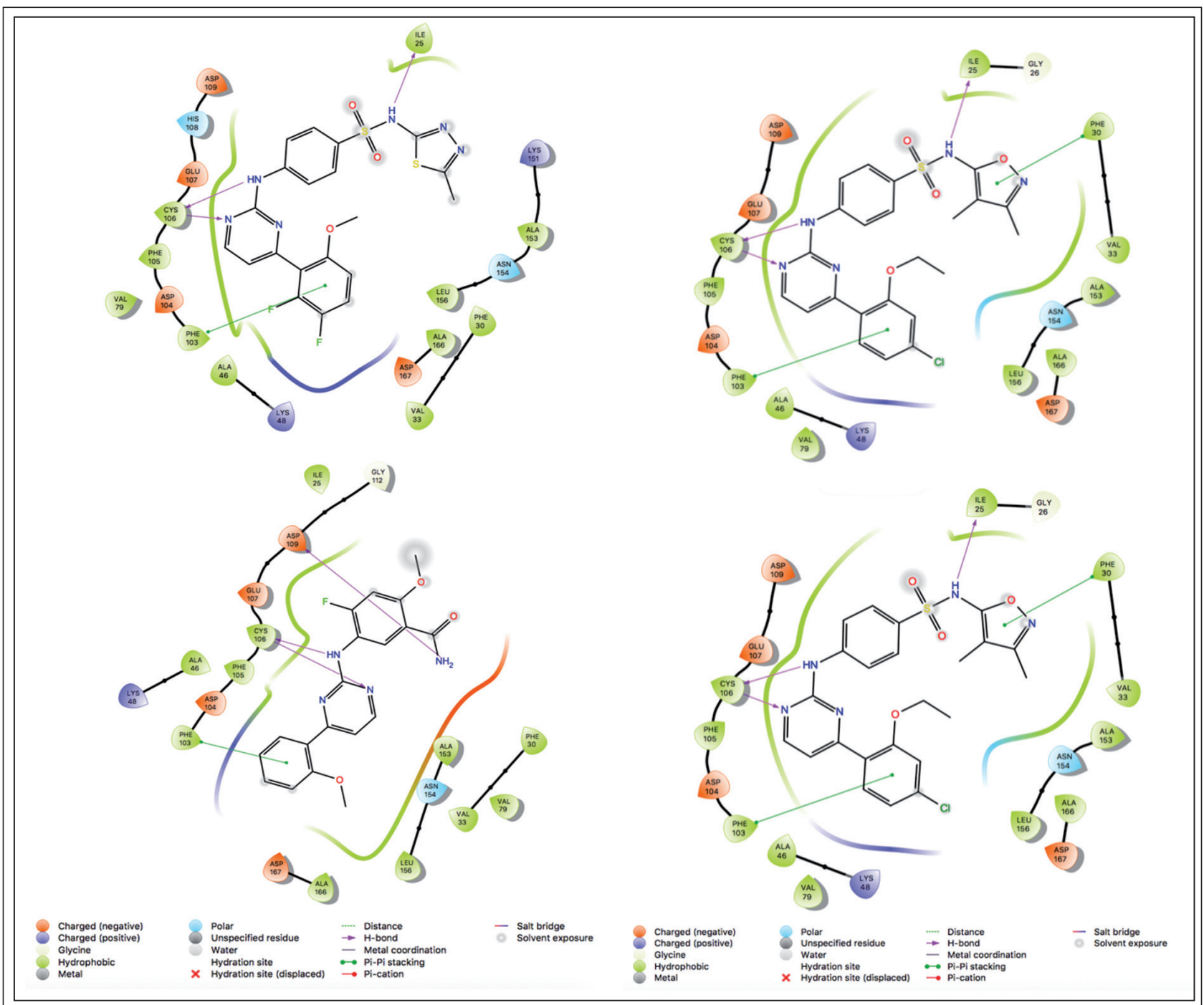

Figure 5 Ligand interaction diagrams showing the most common interactions between the inhibitors and the binding site 
Table III Docking scores

\begin{tabular}{|c|c|c|c|}
\hline ID & $\mathrm{pIC}_{50}$ & XP docking score & SP docking score \\
\hline 54 & 9.398 & -11.387 & -9.498 \\
\hline 25 & 8.097 & -11.184 & -9.245 \\
\hline 32 & 7.770 & -11.134 & -8.702 \\
\hline 35 & 7.886 & -11.046 & -9.294 \\
\hline 33 & 7.310 & -11.026 & -9.435 \\
\hline 28 & 7.602 & -10.943 & -8.737 \\
\hline 27 & 7.921 & -10.942 & -9.366 \\
\hline 42 & 8.523 & -10.928 & -9.257 \\
\hline 30 & 8.097 & -10.914 & -9.326 \\
\hline 68 & 8.699 & -10.912 & -9.891 \\
\hline 40 & 7.301 & -10.911 & -9.158 \\
\hline 37 & 7.959 & -10.911 & -9.453 \\
\hline 26 & 9.000 & -10.897 & -9.740 \\
\hline 67 & 8.699 & -10.883 & -9.250 \\
\hline 53 & 8.000 & -10.855 & -9.208 \\
\hline 22 & 8.699 & -10.850 & -9.248 \\
\hline 24 & 9.000 & -10.833 & -9.610 \\
\hline 34 & 6.339 & -10.830 & -9.195 \\
\hline 46 & 8.699 & -10.815 & -9.120 \\
\hline 23 & 8.046 & -10.812 & -8.876 \\
\hline 39 & 7.260 & -10.757 & -9.265 \\
\hline 52 & 8.699 & -10.753 & -9.447 \\
\hline 36 & 8.222 & -10.751 & -9.288 \\
\hline 50 & 8.222 & -10.715 & -9.113 \\
\hline 51 & 8.046 & -10.700 & -9.225 \\
\hline 56 & 8.699 & -10.690 & -9.373 \\
\hline 43 & 8.301 & -10.676 & -9.136 \\
\hline 48 & 6.423 & -10.657 & -8.986 \\
\hline 47 & 6.678 & -10.653 & -9.389 \\
\hline 21 & 8.523 & -10.632 & -9.262 \\
\hline 49 & 7.921 & -10.572 & -9.092 \\
\hline 57 & 8.301 & -10.522 & -9.082 \\
\hline 45 & 6.914 & -10.491 & -9.155 \\
\hline 44 & 7.481 & -10.462 & -9.225 \\
\hline 66 & 8.523 & -10.311 & -9.472 \\
\hline 31 & 8.699 & -10.265 & -9.659 \\
\hline 38 & 7.678 & -10.135 & -9.140 \\
\hline 58 & 5.802 & -10.012 & -8.837 \\
\hline 29 & 8.046 & -9.936 & -8.947 \\
\hline 42 & 8.398 & -9.907 & -8.795 \\
\hline 55 & 7.854 & -9.749 & -9.238 \\
\hline
\end{tabular}

introducing various substituents at the ends of the molecule can lead to changes in activity. The steric contour map (Figure 3b) suggested that a bulky group at $\mathrm{C}-12$ on the thiadiazole ring could be a good way the improve binding, while substitution at C-18 may be disadvantageous. From the electrostatic field contour map (Figure 3c) we could conclude that electrostatic groups at C-12, 19 and 20 may increase the activity while at C-22 an electronegative group could lead to a similar result. Judging from Figure $3 d$, the introduction of a hydrogen bond acceptor moiety near C-20 and N-13 could also possibly improve the inhibition of CDK9. After having a look at Figure $3 e$ it is easy to see that a hydrophobic substituent at C-19, 22 and 23 could be desirable in order to increase the inhibitor activity.

\subsection{Docking}

Each ligand of our compound set was docked into the binding pocket of $4 \mathrm{BCF}$. As expected, XP scores were better than SP scores, however, no real correlation with the biological data was found as some lower activity compounds (eg. 34, 47, 48 and 58 ) were overscored (especially in terms of the XP method), which may be caused by the relatively low resolution of the $\mathrm{X}$-ray structure.

As it can be seen in Figure $4 \mathrm{a}$, the docked ligands are very well aligned and fit in the binding pocket quite easily. Every ligand formed two Hbonds with Cys106 (both as a hydrogen bond donor and acceptor), while Ile25 usually acted as a hydrogen bond acceptor. Phe30 often had a $\pi-\pi$ stacking with heterocyclic rings such as thiazoles or isoxazols, while Phe103 was often involved in a $\pi-\pi$ stacking interaction with one of the aromatic rings. In some cases His108 and Asp109 also formed secondary bonds with the inhibitors. Similarly to the co-crystallized inhibitor, the conformation of our compounds was bent and usually parts like the sulfonamide group, triazole and isoxazole rings were solvent exposed as they were (at least partially) positioned outside of the binding pocket granting more conformational freedom for these moieties, but as a result they were less likely to establish connections with the protein. Although they are not shown in this figure, there was a significant amount of Van der Waals bonds between the ligands and the protein, which we believe plays a significant role in the binding process, which is in line with our knowledge about the hydrophobic nature of this binding site.

\subsection{Pharmacophore Hypotheses}

Our best pharmacophore model hypotheses 


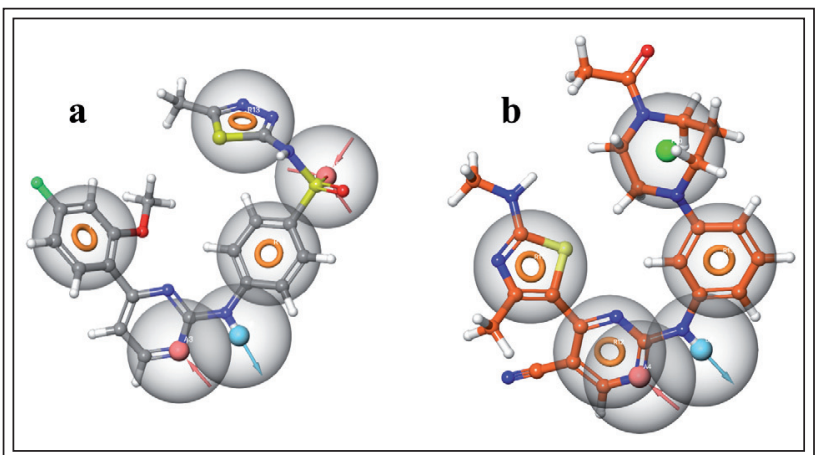

Figure 6 Comparison of pharmacophore models a: Our best (AADRRR) pharmacophore hypothesis superimposed on compound $54 \mathrm{~b}$ : Pharmacophore hypothesis developed from the $4 B C F$ co-crystallized ligand

were obtained using the superposition of the conformations obtained from the XP docking poses. The knowledge we got from the docking experiments was also taken into consideration regarding the selection of pharmacophoric groups. Our best model, AADRRR can be characterized with a Survival score of 6.21 and a Selectivity score of 2.14. The Fitness of compound 54 in this hypothesis was 2.633653. This model contained a hydrogen bond donor (D) and an acceptor (A) at exactly the same position we could observe in the docking part. There were also two rings (R), which were also observed as $\pi-\pi$ interaction participants with the protein. There was another hydrogen bond acceptor (A), namely an oxygen atom in the sulfonamide group. As we saw earlier, this part of the molecule is usually out of the binding pocket, thus less likely forms any bonds. The high scores may indicate that this unique model could be suitable for the identification of new, potentially CDK9 selective inhibitors.As a comparison, a hypothesis based on the co-crystallized ligand was also developed. This model consisted of three aromatic rings $(\mathrm{R})$, one hydrogen bond donor (D) and one acceptor (A) and also a hydrophobic region (Figure 6b). It must be pointed out, that despite the structural differences of the inhibitors, these hypotheses showed some significant similarities (four out eight groups had a perfect match), which further indicates the validity of our model.

\section{Conclusions}

Based on a previously published CDK9 X-ray structure and 41 CDK9 inhibitor compounds, a docking study was completed. Our investigations also included ligand-based pharmacophore-, and QSAR modeling studies. Judging from our best pharmacophore hypothesis and the docking poses, a hydrogen bond donor and acceptor at close proximity are essential in the binding, because they both interact with the backbone atoms of Cys106. These interactions presumably help to fasten the compound in the binding pocket. According to our opinion, the orientation and presence of the aromatic rings could also be important, because they are able to form $\pi-\pi$ interactions with Phe30 and Phe103. The importance of the sulfonamide group lies in the fact, that its $\mathrm{NH}$ group is able to form a hydrogen bond with Ile25, while other components of the inhibitors like thiazoleand dimethylisoxazole groups are usually unbound so their orientations were varied in the poses. The bent conformation of the ligands and the shape and surface of the binding pocket are also key factors that determine the nature of the interactions between CDK9 and its inhibitors. To sum up, we generated a pharmacophore hypothesis and determined the main features of these molecules that play a role in their activity as inhibitors. Then we docked all of these compounds to deepen our understanding of the binding, and reveal new interactions and connections, and finally we built a robust field-based QSAR model with a strong predictive power, which might be able to predict the activity of inhibitor candidates in the future. If we apply the three above detailed methods in the right order, it gives us a powerful tool that can facilitate our CDK9 inhibitor research. We could screen databases and compound libraries by using our pharmacophore hypothesis. After that we could dock the selected ligands to compare their ability to bind to CDK9 and finally test them with a QSAR model to predict their activities. We are confident that all the models and knowledge that we gathered by this project can improve the CDK9 inhibitor design and can lead to new and - after completing the protocol with further targets - probably more selective inhibitors. We also believe that our method can reduce time and costs of CDK9 inhibitor drug development and can assist in lead selection and optimization.

\section{ACKNOWLEDGEMENTS}

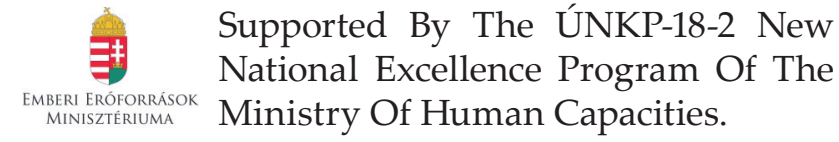




\section{REFERENCES}

1. Malumbres M. Cyclin-dependent kinases. Genome Biol. 2014;15(6):122. https://doi.org/10.1186/gb4184

2. Lim S, Kaldis P. Cdks, cyclins and CKIs: roles beyond cell cycle regulation. Dev Camb Engl. 2013 Aug;140(15):3079-93. dev.091744

3. Liu $\mathrm{H}$, Herrmann $\mathrm{CH}$. Differential localization and expression of the Cdk9 42k and 55k isoforms. J Cell Physiol. 2005 Apr;203(1):251-60. https://doi. org/10.1002/jcp.20224

4. De Luca A, De Falco M, Baldi A, Paggi MG. Cyclin T: three forms for different roles in physiological and pathological functions. J Cell Physiol. 2003 Feb;194(2):101-7. https://doi.org/10.1002/ jсp.10196

5. Baumli S, Lolli G, Lowe ED, Troiani S, Rusconi $\mathrm{L}$, Bullock AN, et al. The structure of P-TEFb (CDK9/cyclin T1), its complex with flavopiridol and regulation by phosphorylation. EMBO J. 2008 Jul 9;27(13):1907-18.https://doi.org/10.1038/emboj.2008.121

6. Bossemeyer D. Protein kinases--structure and function. FEBS Lett. 1995 Aug 1;369(1):57-61. https:// doi.org/10.1016/0014-5793(95)00580-3

7. Hanks SK, Hunter T. Protein kinases 6. The eukaryotic protein kinase superfamily: kinase (catalytic) domain structure and classification. FASEB J Off Publ Fed Am Soc Exp Biol. 1995 May;9(8):576-96. https://doi.org/10.1096/fasebj.9.8.7768349

8. Li Q, Price JP, Byers SA, Cheng D, Peng J, Price DH. Analysis of the large inactive $\mathrm{P}-\mathrm{TEFb}$ complex indicates that it contains one 7SK molecule, a dimer of HEXIM1 or HEXIM2, and two P-TEFb molecules containing Cdk9 phosphorylated at threonine 186. J Biol Chem. 2005 Aug 5;280(31):28819-26. https:// doi.org/10.1074/jbc.M502712200

9. Wang S, Fischer PM. Cyclin-dependent kinase 9: a key transcriptional regulator and potential drug target in oncology, virology and cardiology. Trends Pharmacol Sci. 2008 Jun;29(6):302-13. https://doi. org/10.1016/j.tips.2008.03.003

10. Bose P, Simmons GL, Grant S. Cyclin-dependent kinase inhibitor therapy for hematologic malignancies. Expert Opin Investig Drugs. 2013 Jun;22(6):723-38. https://doi.org/10.1517/13543784. 2013.789859

11. Peterlin BM, Brogie JE, Price DH. 7SK snRNA: a noncoding RNA that plays a major role in regulating eukaryotic transcription. Wiley Interdiscip Rev RNA. 2012 Feb;3(1):92-103. https://doi.org/10.1002/ wrna.106
12. Meijer L, Borgne A, Mulner O, Chong JP, Blow JJ, Inagaki $\mathrm{N}$, et al. Biochemical and cellular effects of roscovitine, a potent and selective inhibitor of the cyclin-dependent kinases cdc2, cdk2 and cdk5. Eur J Biochem. 1997 Jan 15;243(1-2):527-36. https://doi. org/10.1111/j.1432-1033.1997.t01-2-00527.x

13. Sonawane YA, Taylor MA, Napoleon JV, Rana S, Contreras JI, Natarajan A. Cyclin Dependent Kinase 9 Inhibitors for Cancer Therapy. J Med Chem. 2016 Oct 13;59(19):8667-84. https://doi.org/10.1021/ acs.jmedchem.6b00150

14. Vijayaraghavan S, Moulder S, Keyomarsi K, Layman RM. Inhibiting CDK in Cancer Therapy: Current Evidence and Future Directions. Target Oncol. 2018 Feb;13(1):21-38. https://doi.org/10.1007/ s11523-017-0541-2

15. Rajput S, Khera N, Guo Z, Hoog J, Li S, Ma CX. Inhibition of cyclin dependent kinase 9 by dinaciclib suppresses cyclin B1 expression and tumor growth in triple negative breast cancer. Oncotarget. 2016 Aug 30;7(35):56864-75. https://doi.org/10.18632/oncotarget.10870

16. Asghar U, Witkiewicz AK, Turner NC, Knudsen ES. The history and future of targeting cyclin-dependent kinases in cancer therapy. Nat Rev Drug Discov. 2015 Feb;14(2):130-46. https://doi.org/10.1038/ nrd 4504

17. Czudor Z, Balogh M, Bánhegyi P, Boros S, Breza N, Dobos J, et al. Novel compounds with potent CDK9 inhibitory activity for the treatment of myeloma. Bioorg Med Chem Lett. 2018 Feb 15;28(4):769-73. https://doi.org/10.1016/j.bmcl.2018.01.002

18. Schrödinger Release 2018-2: Field-based QSAR, Schrödinger, LLC, New York, NY, 2018.

19. Sastry GM, Adzhigirey M, Day T, Annabhimoju $\mathrm{R}$, Sherman W. Protein and ligand preparation: parameters, protocols, and influence on virtual screening enrichments. J Comput Aided Mol Des. 2013 Mar;27(3):221-34. https://doi.org/10.1007/ s10822-013-9644-8

20. Shivakumar D, Williams J, Wu Y, Damm W, Shelley J, Sherman W. Prediction of Absolute Solvation Free Energies using Molecular Dynamics Free Energy Perturbation and the OPLS Force Field. J Chem Theory Comput. 2010 May 11;6(5):1509-19. https://doi.org/10.1021/ct900587b

21. Dixon SL, Smondyrev AM, Knoll EH, Rao SN, Shaw DE, Friesner RA. PHASE: a new engine for pharmacophore perception, 3D QSAR model development, and 3D database screening: 1. Methodology and preliminary results. J Comput Aided Mol Des. 2006 Nov;20(10-11):647-71. https://doi.org/10.1007/ s10822-006-9087-6 